\title{
SHuffle, a novel Escherichia coli protein expression strain capable of correctly folding disulfide bonded proteins in its cytoplasm
}

\author{
Julie Lobstein ${ }^{1}$, Charlie A Emrich², Chris Jeans ${ }^{3}$, Melinda Faulkner ${ }^{4}$, Paul Riggs ${ }^{1}$ and Mehmet Berkmen ${ }^{1,5^{*}}$
}

\begin{abstract}
Background: Production of correctly disulfide bonded proteins to high yields remains a challenge. Recombinant protein expression in Escherichia coli is the popular choice, especially within the research community. While there is an ever growing demand for new expression strains, few strains are dedicated to post-translational modifications, such as disulfide bond formation. Thus, new protein expression strains must be engineered and the parameters involved in producing disulfide bonded proteins must be understood.

Results: We have engineered a new E. coli protein expression strain named SHuffle, dedicated to producing correctly disulfide bonded active proteins to high yields within its cytoplasm. This strain is based on the trxB gor suppressor strain SMG96 where its cytoplasmic reductive pathways have been diminished, allowing for the formation of disulfide bonds in the cytoplasm. We have further engineered a major improvement by integrating into its chromosome a signal sequenceless disulfide bond isomerase, DsbC. We probed the redox state of DsbC in the oxidizing cytoplasm and evaluated its role in assisting the formation of correctly folded multi-disulfide bonded proteins. We optimized protein expression conditions, varying temperature, induction conditions, strain background and the co-expression of various helper proteins. We found that temperature has the biggest impact on improving yields and that the E. coli B strain background of this strain was superior to the K12 version. We also discovered that auto-expression of substrate target proteins using this strain resulted in higher yields of active pure protein. Finally, we found that co-expression of mutant thioredoxins and PDI homologs improved yields of various substrate proteins.
\end{abstract}

Conclusions: This work is the first extensive characterization of the trxB gor suppressor strain. The results presented should help researchers design the appropriate protein expression conditions using SHuffle strains.

Keywords: SHuffle, Protein expression strain, Disulfide bond formation, Disulfide bond isomerization, DsbC, trxB, gor, $\operatorname{ahpC^{*}}$

\section{Background}

Many research applications require the purification of high yields of an active and correctly folded protein for either its study (biochemical analysis, X-ray crystallography, etc.), or for its direct use (e.g. as in therapeutic and diagnostic applications). In general, protein overexpression, and the generation of high yields is oftentimes difficult and unpredictable. It becomes even more arduous when the protein of interest contains post-translational modifications, such

\footnotetext{
* Correspondence: berkmen@neb.com

${ }^{1}$ New England Biolabs, Ipswich, MA 01938, USA

${ }^{5}$ New England Biolabs, 240 County road, Ipswich, MA 01938, USA

Full list of author information is available at the end of the article
}

as disulfide bonds, which are critical for proper protein folding, stability, and/or activity. Disulfide bonds are formed by the oxidation of sulfhydryl groups between two cysteine side chains resulting in a covalent bond, greatly increasing the stability of a protein. A large proportion of proteins contain disulfide bonds. For example, analysis of the human genome revealed that $30 \%$ of the proteins are predicted to be targeted to the endoplasmic reticulum (ER) where disulfide bond formation is compartmentalized and of those, half are predicted to form disulfide bonds [1]. Since disulfide bonds increase the stability of proteins, most disulfide-bonded proteins are secreted or remain anchored to the plasma membrane, exposed to the environment. This feature of disulfide-bonded proteins

\section{Biomed Central}


makes them excellent therapeutic agents or targets for the pharmaceutical industry. Recent market analysis of therapeutic proteins indicates that all classes of therapeutic proteins are composed mostly or exclusively of proteins containing disulfide bonds [2]. It is therefore critical to have multiple expression systems which can express disulfide-bonded proteins rapidly with relative ease and low cost. Additional molecular tools must also be developed to fine tune the protein expression conditions for a given substrate protein, to achieve maximal yields to high purity.

Currently there are several expression systems available for the production of disulfide-bonded proteins, with each system having its own advantages and disadvantages. Although eukaryotic expression systems such as Chinese Hamster Ovary (CHO), yeast or insect cells offer the capacity to express complex multi-disulfide-bonded proteins, these systems are slow and expensive. Cell-free expression systems may have circumvented the problem of speed but are not feasible for scale-up. For most applications, prokaryotic expression remains the most attractive expression system due to its relatively low cost, high speed, ease of use, high yields, and the availability of large numbers of genetic tools for optimization purposes.

Escherichia coli is the most popular choice for recombinant protein production. Currently there are only a handful of $E$. coli expression strains commercially available. There is an ever growing demand for new, versatile and improved protein expression strains, especially those that are engineered to handle post-translational modifications such as disulfide bond formation. So far, production of soluble and active disulfide-bonded proteins to high yields in $E$. coli remains a challenge. This is mainly due to the fact that for most overexpression systems, the recombinant protein produced is expressed in the cytoplasm, but disulfide bond formation is compartmentalized to the periplasm where $E$. coli is poorly adapted for producing multidisulfide bonded proteins in high yields. Since all living cells studied to date have enzymes dedicated to reducing disulfide bonds in their cytoplasm, the formation of disulfide bonds have been compartmentalized to extra-cytoplasmic compartments such as the periplasm in gram negative bacteria [3] or the ER in eukaryotes [4]. Thus, proteins which require disulfide bonds for their folding and stability are poorly expressed, misfolded, and are not active when expressed in the cytoplasm of E. coli.

A major breakthrough came through the pioneering work conducted by Beckwith and co-workers during their studies into the redox pathways of $E$. coli [5-8]. The culmination of their work along with several other labs elucidated the cytoplasmic redox pathways and enzymes in E. coli. This knowledge enabled the Beckwith lab to engineer a mutant $E$. coli strain capable of promoting disulfide bond formation in the cytoplasm [9].
The formation of a disulfide bond is catalyzed by enzymes belonging to the thioredoxin super-family [10]. In E.coli, disulfide bond formation is catalyzed in the periplasmic space by the enzyme DsbA [3]. DsbA is one of the strongest oxidases measured and will oxidize cysteine residues consecutively as they enter the periplasm [11,12]. Proteins which require multiple nonconsecutive disulfide bonds require the action of a disulfide bond isomerase to shuffle the disulfide bonds within the mis-oxidized protein to produce its native folded state $[13,14]$. E. coli's periplasmic disulfide bond isomerase is DsbC, a homodimeric "V" shaped protein, where each arm of the "V" is a thioredoxin fold brought together by a dimerization domain [15]. The cleft formed by the V-shaped DsbC is hydrophobic, thought to preferentially interact with mis-oxidized proteins that have their core hydrophobic residues exposed. This hydrophobic cleft is also hypothesized to mediate the chaperone property of DsbC, which is independent of its redox active cysteines [16]. Over-expression of DsbC greatly enhances the amount of correctly folded protein in vivo both in the periplasm $[17,18]$ and in the cytoplasm $[8,19,20]$. Incubation of DsbC in vitro in cell free expression systems has also been shown to enhance the amounts of correctly folded disulfide bonded proteins [21,22].

The engineering of an $E$ coli strain to produce large quantities of cytoplasmic protein with disulfide bonds would require engineering of the two reductive pathways (thioredoxin and glutaredoxin/glutathione) in the cytoplasm. Due to the presence of numerous thiol reductases (Grx1, Grx2, Grx3, Trx1, Trx2), glutathione, and small thiol reductants, cysteines are maintained in their reduced state in the cytoplasm of wild type E. coli and are not able to form stable disulfide bonds (they may still form transiently [23-25]). To genetically engineer a strain that allows the formation of stable disulfide bonded proteins within the cytoplasm, thioredoxin reductase $(\operatorname{tr} x B)$ and glutathione reductase (gor) were mutated. Mutant $E$. coli cells carrying deletions of trxB gor are nonviable as certain essential proteins, such as ribonucleotide reductase, cannot be re-cycled back to their active reduced states [26]. A suppressor screen for $\operatorname{trx} B$ gor lethality generated a strain (FÅ113) whose mutant peroxidase $\mathrm{AhpC}^{*}$ had gained the ability to reduce Grx1, restoring reducing power to the cell [7]. Thioredoxins remain in their oxidized state and can oxidize protein substrates which require disulfide bonds for their folding [6]. This mutant E. coli strain (FA113) is sold commercially under the name Origami by Novagen. However, in this strain, thioredoxins, like DsbA, form disulfide bonds indiscriminately, resulting in some proteins being mis-oxidized and inactive. A marked increase in activity of some cytoplasmically expressed proteins was observed when DsbC 
lacking its signal sequence was co-expressed in the cytoplasm $[8,9,27]$. Recently, co-expression of the yeast sulfhydryl oxidase Erv1p has also been shown to improve production of disulfide bonded proteins in the cytoplasm of E. coli $[28,29]$. Even though this work demonstrates the various methods of producing disulfide bonded proteins, expression of cytoplasmic DsbC was still crucial in achieving high yields of correctly folded substrate protein. While this method is in its infancy, utility of this system has already been demonstrated [30].

The E. coli trxB gor suppressor has been a useful strain for producing disulfide bonded proteins resulting in hundreds of publications since the utility of this strain was first shown in 1999 [8]. However, no comprehensive study has been conducted on the parameters involved in producing correctly folded protein within this strain. Furthermore, although the co-expression of cytoplasmic DsbC had been shown to improve protein folding [20], no such strain was engineered nor studied in detail. Here, we present a novel protein expression strain based on a different trxB gor suppressor strain (SMG96). We engineered this strain to cytoplasmically over-express DsbC under the relatively strong and highly-regulated rRNA promoter $r r n B$ [31]. We characterized the redox state of the strain and investigated the effects of varying three common parameters (temperature, time and strength of induction) on protein expression. Using the optimized conditions, we expressed and purified eight different substrate proteins and showed their relative solubility. Finally, we co-expressed a set of helper proteins and evaluated their ability to increase the folding of a subset of proteins. This strain is currently commercially available under the name SHuffle from New England Biolabs.

\section{Results \\ Redox state of SHuffle cells are altered to permit oxidative folding}

We constructed a mutant E. coli strain with an altered redox state that permits the formation of stable disulfide bonds within its cytoplasm. This strain's parent is the previously described E. coli strain SMG96 [32] which itself is based on the strain F尺113 [8]. SMG96 lacks the gor and $\operatorname{tr} x B$ reductases; the lethality conferred by these mutations is suppressed by a mutation in the peroxidase $a h p C^{*}$ [7]. Figure 1 shows a schematic of this altered redox pathway which results in the reduction of Grx1 by AhpC ${ }^{*}$, restoring viability. Trx1 remains oxidized and therefore catalyzes the formation of disulfide bonds within the cytoplasm (Figure 1B). We have further engineered the strain to express DsbC in the cytoplasm, which should isomerize mis-oxidized proteins to their native states (Figure 1C).

\section{Expression cytoplasmic DsbC in SHuffle can improve oxidative folding}

DsbC is an oxido-reductase chaperone, capable of enhancing the oxidative folding of proteins both in its native periplasmic compartment and when expressed cytoplasmically $[8,19,20]$. To investigate the role of cytoplasmic DsbC in SHuffle cells, we compared the activity of three different proteins which require disulfide bonds to achieve their native folded state (Figure 2). Gaussia luciferase has 10 cysteines which are all involved in disulfide bonds, although the pattern of disulfide bonds remains unknown [33]. As schematically depicted in Table 1, urokinase and vtPA both have non-consecutive disulfide bonds with 18 and 12 cysteines, respectively, making them ideal candidates for testing the role of cytoplasmic DsbC.

We measured the activities of the three candidate enzymes in four different strain backgrounds to determine what effects an oxidizing cytoplasm and the presence of DsbC in the cytoplasm have on their activity. As expected, no or very little enzyme activity was detected in cell lysates lacking the gene of interest (GOI) (Figure 2 lane 1, 5 and 9). A similar lack of enzyme activity was observed in wild type $E$. coli, suggesting that the proteins do not fold correctly in a normal reducing cytoplasm (Figure 2, lane 2, 6 and 10). In contrast, when we expressed the enzymes in an oxidizing cytoplasm, we observed a marked increase in activity for luciferase and urokinase but not for vtPA (Figure 2, lane 3 and 7), suggesting that an oxidizing cytoplasm is sufficient for the correct folding of only some proteins that contain disulfide bonds (Figure 2, lane 11). Cytoplasmic DsbC increased the activity for two of the three candidates. Urokinase activity slightly increased in the presence of DsbC (Figure 2, lane 8), whereas vtPA was completely dependent on DsbC for proper folding (Figure 2, lane 12). Luciferase activity was reduced almost two-fold in the presence of DsbC (Figure 2, lane 4). These results suggest that DsbC can be absolutely essential for folding of certain protein substrates. We suggest that SHuffle is an important strain background for researchers to use when expressing disulfide-bonded proteins that display low activity in other strain backgrounds. Furthermore, we conclude that SHuffle's effect on the folding of disulfide-bonded proteins is substrate protein specific.

\section{Expression of proteins in SHuffle B strains results in greater yields compared to SHuffle K12 strains}

During the course of our experiments, we noticed differences in the activities of proteins measured from SHuffle cells constructed in the K12 vs. the B strain backgrounds. In order to determine that the differences were not due to growth rate, we measured growth of cultures at $30^{\circ} \mathrm{C}$. We observed no significant difference in growth rate between SHuffle cells and their parental 


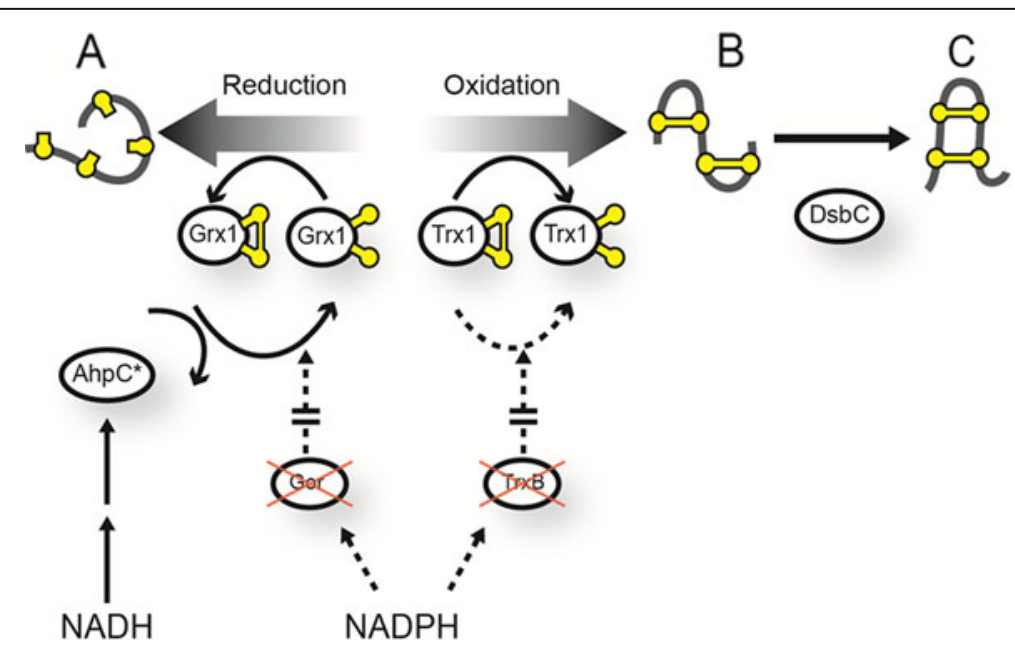

Figure 1 Disulfide bond formation in the cytoplasm of SHuffle. Schematic diagram of the redox pathways in the cytoplasm of SHuffle. Dotted lines represent disabled protein interactions due to the deletion of $\operatorname{trx} B$ and gor. Redox state of cysteines (yellow balls) are indicated (oxidized = ball + stick; reduced = ball). (A) Protein is reduced by Grx1 or oxidized by Trx1. (B) Mis-oxidized protein is isomerized to its native correctly folded state (C) by DsbC.

wild type (Additional file 1). To directly compare the effect of strain background, we measured the activities of three different substrate proteins expressed in either
SHuffle K12 (C3025 or C3026) or SHuffle B (C3028 or C3029) (Figure 3). Luciferase and urokinase activities were approximately 2 -fold higher in the B background

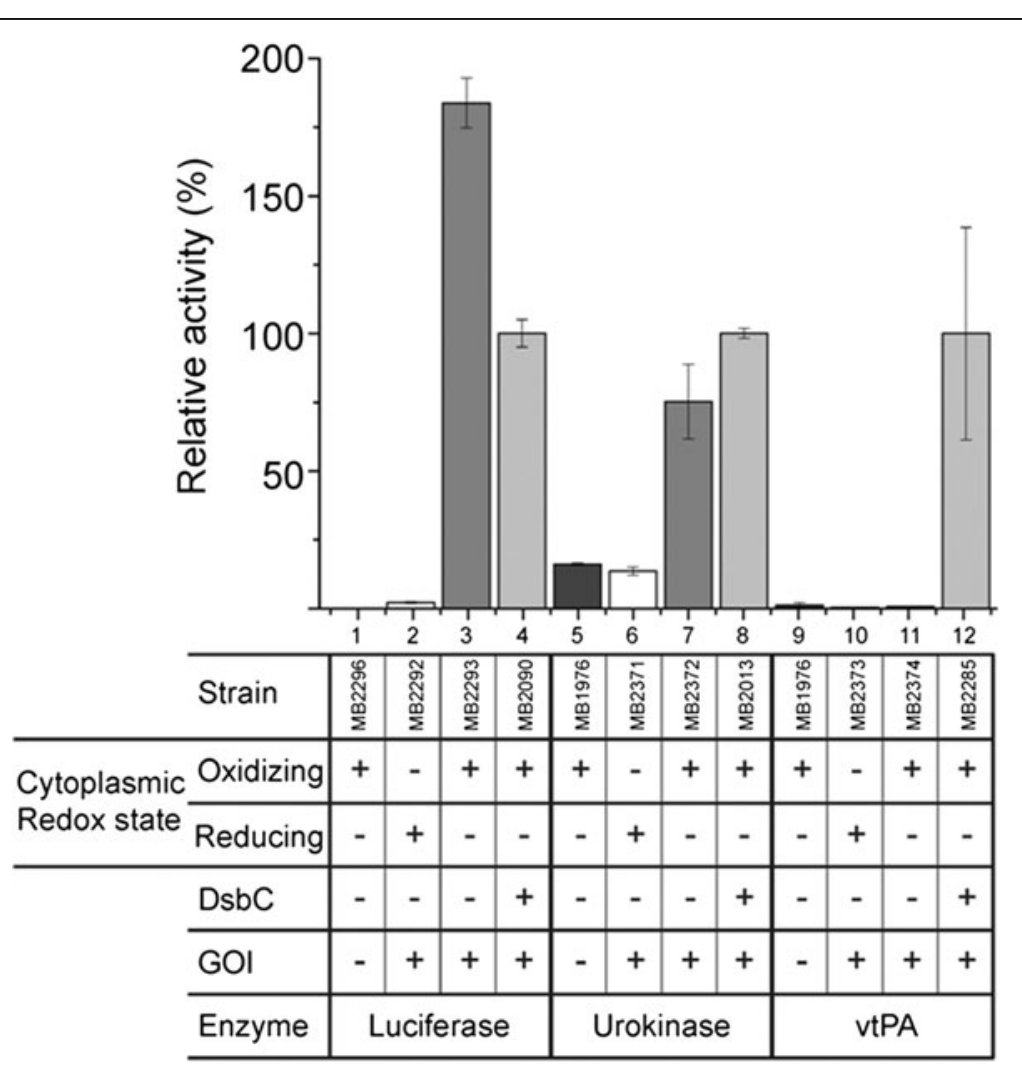

Figure 2 Influence of cytoplasmic DsbC on three different proteins in SHuffle. Relative enzymatic activities of various proteins (luciferase, urokinase, vtPA) measured from crude lysates. Cytoplasmic redox state, presence of cytoplasmic DsbC and gene of interest (GOI) are indicated. 
Table 1 Table summarizing optimum expression conditions for all proteins produced in SHuffle

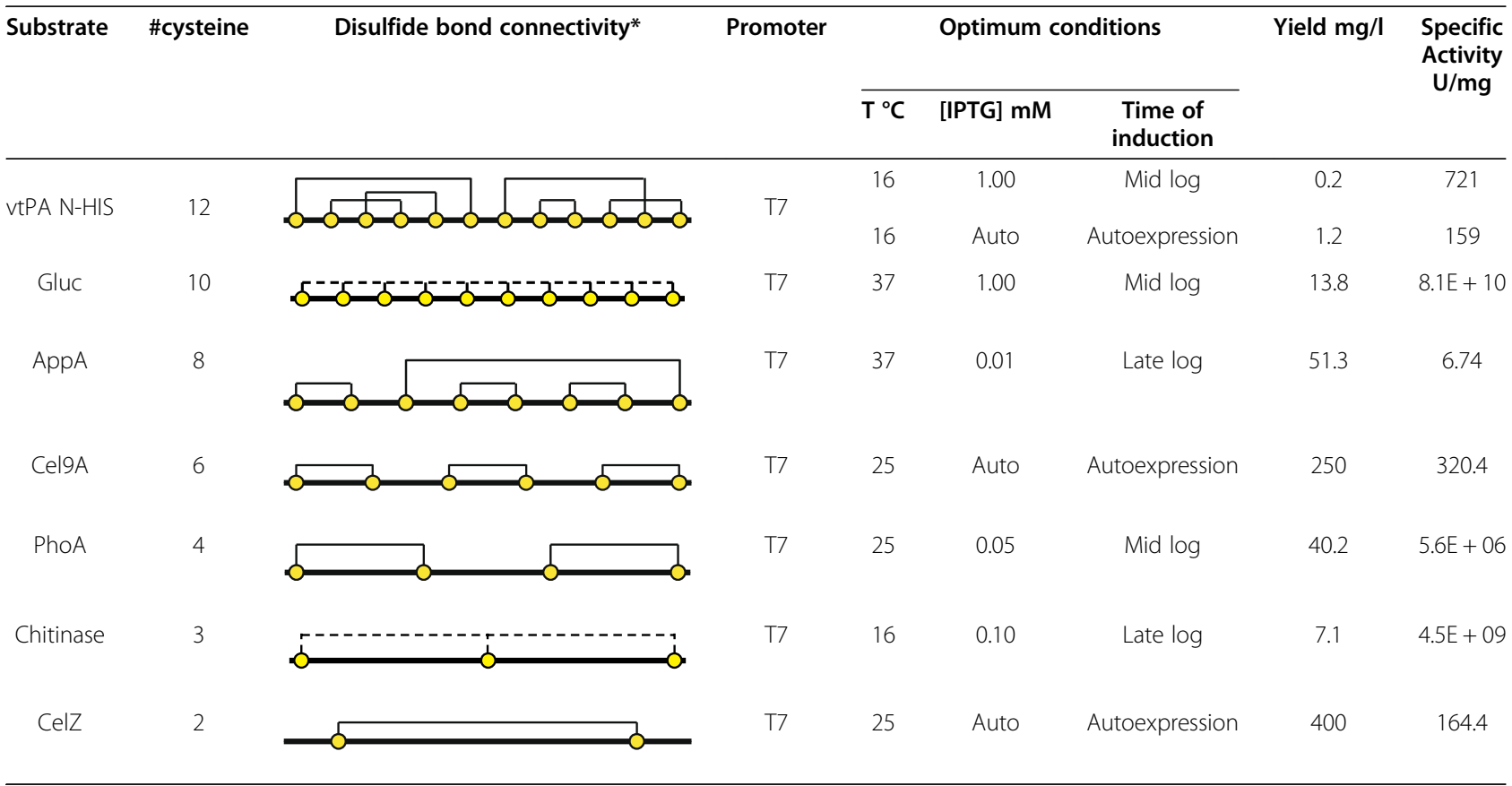

* Solid lines represent known disulfide bonds from crystal structures, dotted lines represent cysteines predicted to be involved in disulfide bonds with unknown structures.

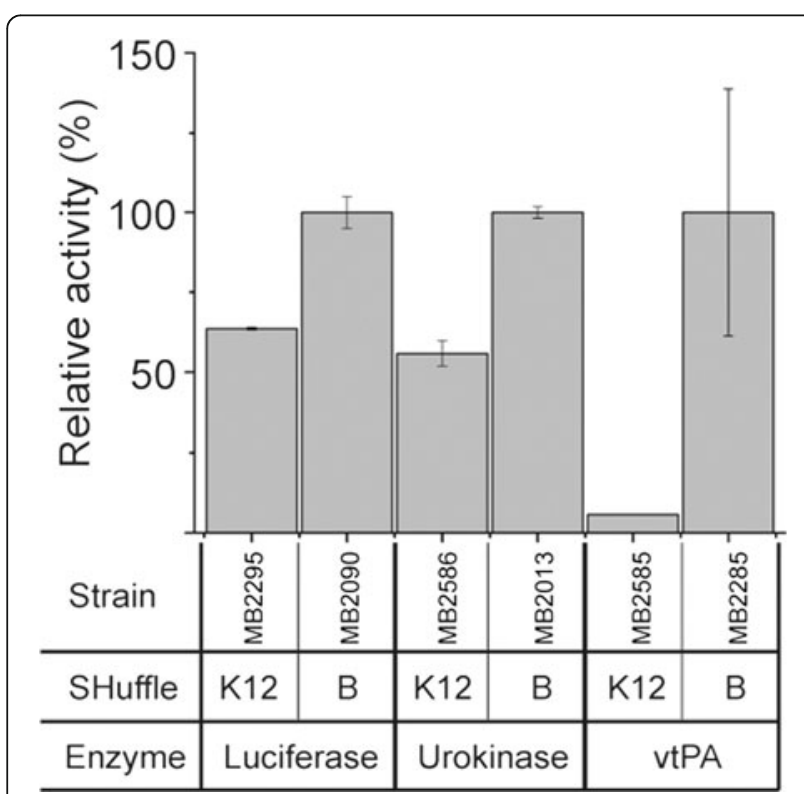

Figure 3 Comparison of relative enzymatic activities in SHuffle (E. coli K12 : C3025 or C3026) and SHuffle express (E. coli B : C3028 or C3029). Relative enzymatic activities of various proteins (luciferase, urokinase, vtPA) measured from crude lysates of various SHuffle strains in the K12 or B strain backgrounds. than in K12. Expression of vtPA did not result in any detectable activity when produced in the K12 background, but was active in the B background. We confirmed our observation with western blot analysis and detected vtPA only in SHuffle B strains and not in SHuffle K12 (Supplementary material Figure 2). Thus, in the case of all three substrate proteins, we observed consistently higher enzyme activities in SHuffle B strains compared to K12.

We wished to explore whether the observed differences were due to differences in the mechanism of suppression of $\operatorname{tr} x B$ gor lethality. Therefore, we sequenced the $a h p C$ gene in SHuffle K12, SHuffle B, their parental wild type strains, and 16 new suppressors isolated using the method described previously [32]. While SHuffle K12 contained the previously described triplet codon expansion $a h p C^{*}$ allele [7], 15 out of the 16 newly isolated SHuffle B strains had a novel triplet codon contraction allele $\left(a h p C^{\Delta}\right)$ and only one isolate had the classic triplet codon expansion (Table 2). We did not observe any significant difference in vtPA activity in SHuffle B $a h p C^{*}$ versus $a h p C^{\Delta}$ cells (data not shown). Even though the mechanism of disulfide bond formation did not appear to vary between the two suppressors, E. coli $\mathrm{K} 12$ and B might have distinct cellular responses to oxidative stress. To test this hypothesis, we grew cells in microtiter dishes with varying amounts of hydrogen peroxide. E. coli B cells ceased to grow at 
Table 2 Genomic sequence of $a h p C$ in various SHuffle strains

\begin{tabular}{lcccccccc}
\hline \multirow{1}{*}{ Strain } & amino acid \# & $\mathbf{3 4}$ & $\mathbf{3 5}$ & $\mathbf{3 6}$ & $\mathbf{3 7}$ & $\mathbf{3 8}$ & $\mathbf{3 9}$ & $\mathbf{4 0}$ \\
\cline { 2 - 9 } & amino acid & Ser & Val & Phe & Phe & Phe & Tyr & Pro \\
\hline wt E. coli K12 and B & $a h p C$ & AGC & GTC & TTC & TTC & TAC & CCG \\
SHuffle K12 & $a h p C^{*}$ & AGC & GTC & TTC & TTC & TTC & TTC & TAC \\
SHuffle B & $a h p C^{\Delta}$ & AGC & GTC & TTC & & TCG & TAC & CCG \\
\hline
\end{tabular}

concentrations above $4 \mathrm{mM}$ hydrogen peroxide, while E. coli $\mathrm{K} 12$ strains ceased to grow above $10 \mathrm{mM}$ hydrogen peroxide (data not shown). We also compared the hydrogen peroxide sensitivity of SHuffle B cells having either $a h p C^{*}$ or $a h p C^{\Delta}$ suppressors mutations. Both strains displayed similar levels of sensitivity and ceased to grow at hydrogen peroxide concentrations above $6 \mathrm{mM}$ (data not shown). Thus, we conclude that the differences in enzyme activities observed for $\mathrm{K} 12$ and $\mathrm{B}$ strains (Figure 3) are not due to the nature of the suppressing mutation in the two strain backgrounds but instead are more likely to be due to general genetic differences between the two strains.

\section{Cytoplasmic DsbC in SHuffle cells are in their active hemi-reduced state}

The redox state of DsbC is critical for its isomerase/ reductase activity both in vivo [34] and in vitro [35]. In order to function as a disulfide bond isomerase, DsbC must be maintained in its hemi-reduced state. Each DsbC monomer contains 4 cysteine residues. The $\mathrm{N}$-terminal redox active cysteines (Cys98-Cys101) face the hydrophobic cleft and are maintained in a reduced form in the periplasm by the inner membrane protein DsbD [34]. The C-terminal pair (Cys140-Cys163) form a stable disulfide bond that is critical for the folding and stability of DsbC [36]. In the absence of DsbD, DsbC becomes oxidized and cannot function as an isomerase/reductase and instead can now function as an oxidase [37]. Unlike the periplasm, the cytoplasm lacks a dedicated reductase such as DsbD to maintain the active site cysteines of DsbC in its reduced state. Furthermore, the reducing/ oxidizing conditions of the cytoplasm of SHuffle cells may not be able to maintain cytoplasmic DsbC in its hemi-reduced state. It is therefore critical to understand the exact redox state of cytoplasmic DsbC in SHuffle cells.

We investigated the redox state of DsbC using AMS alkylation followed by western blot analysis using antiDsbC antibody (Figure 4). AMS alkylates any free thiol group found in the side chains of cysteine residues, covalently adding 500 Daltons, resulting in mobility shift in SDS-PAGE analysis. Since SHuffle cells contain both periplasmic and cytoplasmic copies of DsbC, we first investigated the redox state of periplasmic DsbC in the parent strain of SHuffle K12 and SHuffle B. In both wild type E. coli $\mathrm{K} 12$ and B strains, periplasmic DsbC was detected mostly in its active hemi-reduced state at similar levels of expression (Figure 4A, lane 1 and 2). Similar amounts of periplasmic DsbC were detected in K12 and B strains which had the $\operatorname{trx} B$, gor, ahp $C^{*}$ mutations (Figure 4B, lane 1 and 2). Significantly higher amount of hemi-reduced DsbC was detected in SHuffle K12 cells, indicating that cytoplasmic DsbC is overexpressed from the chromosome and is in the correct redox state to function as a disulfide bond isomerase (Figure 4B, lane 3). However, SHuffle B cells did not over-express cytoplasmic DsbC to the same level as SHuffle K12 cells (Figure 4B, lane 4). This may have to do with differential regulation of the $r r n B$ promoter in E. coli B cells in comparison to $E$. coli $\mathrm{K} 12$, since the $r r n B$ promoter controls the expression of cytoplasmic DsbC. In order to understand whether cytoplasmic DsbC is under-expressed and limited in SHuffle B cells, we constructed two more SHuffle B cells in which the DsbC was under the regulation of rrnB promoters with 9 or 70 times higher transcriptional activity [31]. These strains did not show any improvement in the activity of urokinase when compared to SHuffle B, suggesting that cytoplasmic DsbC is sufficiently over-expressed (data not shown).

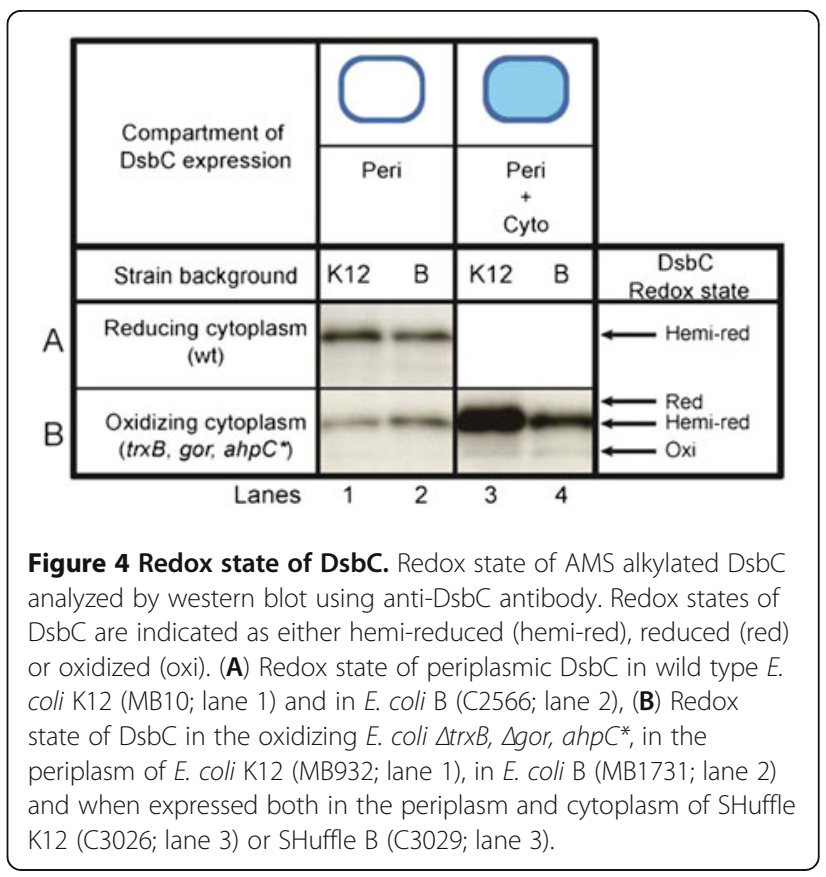


The culmination of these results when combined with the in vivo protein expression data indicates that the majority of cytoplasmic DsbC is active in its hemi-reduced state, essential for its disulfide bond isomerase activity. We also observed significant amounts of oxidized cytoplasmic DsbC in SHuffle cells, which may directly contribute to the oxidation of substrate proteins.

\section{Optimization of protein expression conditions}

To optimize production of proteins in SHuffle cells, we investigated the effects of three parameters on the expression of seven different substrate proteins. In consideration of the average researcher who expresses proteins using a shake flask system with limited time and resources, we chose the three most commonly modified parameters: temperature, time of induction, and concentration of inducer (IPTG).

\section{Temperature}

The effect of temperature on protein folding has been well documented and is one of the most common factors to be optimized during production of proteins [38]. We therefore investigated the role of temperature on protein expression by growing SHuffle cells in rich medium initially at $30^{\circ}$ until the cells reached mid log growth phase. Protein expression was induced with $1 \mathrm{mM}$ IPTG and the growth temperature shifted to $16^{\circ} \mathrm{C}, 25^{\circ} \mathrm{C}, 30^{\circ} \mathrm{C}$ or $37^{\circ} \mathrm{C}$. At the end of exponential growth, activity of the substrate protein was measured. As shown in Table 1, the optimal temperature varied among the seven proteins: for two it was $16^{\circ} \mathrm{C}$, for three it was $25^{\circ} \mathrm{C}$, and for the final two it was $37^{\circ} \mathrm{C}$. We conclude that the effect of temperature was protein specific.

\section{Time of induction}

Using the optimal temperature discovered in the prior experiment, we investigated the effect of inducing at various growth phases. SHuffle cells were grown at the optimal temperature and were induced with $1 \mathrm{mM}$ IPTG at the initial time of inoculation, mid-log or late-log growth phase. Further downstream processes were the same as described above. In the case of the two cellulases (CelZ and Cel9A) an additional method of induction, termed here 'autoexpression' was tried and found to be optimal over standard IPTG induction (Table 1). Autoexpression relies on the diauxic response of $E$. coli when grown in multiple carbon sources such as glucose and lactose, resulting in induction of lac promoter upon depletion of glucose [39]. Using Magic Media supplied by Invitrogen, cells were grown overnight without induction and enzymatic assays were performed the next day. Further characterization of autoexpression was performed by comparing the yields obtained for a poor folding protein such as vtPA, when expressed under optimized IPTG conditions vs. autoexpression. The yields of purified vtPA increased from marginally detectable amounts to over $1 \mathrm{mg} / \mathrm{l}$, indicating that autoexpression may be a suitable method of protein production in SHuffle cells (Table 1).

\section{Concentration of inducer}

Using the optimal expression temperature and time of induction conditions discovered prior, the concentration of inducer was optimized. SHuffle cells were grown at the optimal temperature and were induced with various concentrations of IPTG $(0,0.01,0.05,0.1$ and $1 \mathrm{mM})$ at the optimal growth phase of induction. The optimal concentration of inducer was protein-specific, varying from $0.01 \mathrm{mM}$ to $1 \mathrm{mM}$ (Table 1 ).

An example of this optimization process is shown for vtPA (Figure 5). Using our optimization process, the optimum shake flask expression condition for vtPA was growth at $16^{\circ} \mathrm{C}$ during protein expression, with $1 \mathrm{mM}$ IPTG induction at mid-growth phase. Overall, our results indicate that the optimal conditions for protein expression in SHuffle cells are protein-specific. However, we did note that temperature had the most profound effect and lowering of growth temperature during induction usually resulted in improved yields. While we did not investigate autoexpression systematically with all the proteins, this induction method also gave improved yields where it was used. Thus, a thorough study is required to optimize the expression conditions for any given new protein of interest.

\section{Proteins expressed in SHuffle cells results in diverse levels of solubility}

The solubility of a protein is an important indicator of its correct folding as determined by functional binding [40] or enzymatic [41] assays. Determining a protein's solubility will help guide the researcher design the correct experimental procedure to improve its yield. For example, a protein having only $5 \%$ of the total expressed protein soluble will require optimization of its folding pathway while another protein having $90 \%$ solubility might require increased expression levels to improve yields. We therefore quantified the levels of solubility of each of the proteins we expressed to assess the level of success of folding in SHuffle strains.

Using the panel of seven substrate proteins expressed under the optimum conditions we discovered previously, cell lysates were produced as described in methods. An aliquot of each lysate was removed to represent the total amount of protein (T). Samples were subjected to centrifugation with the supernatant representing the soluble fraction (S) and the pellet representing the insoluble fraction (P). Samples were analyzed by western blot with the appropriate antibody. As a control for proper fractionation, samples were also probed with anti-GroEL antibody to detect the soluble fraction that contains 


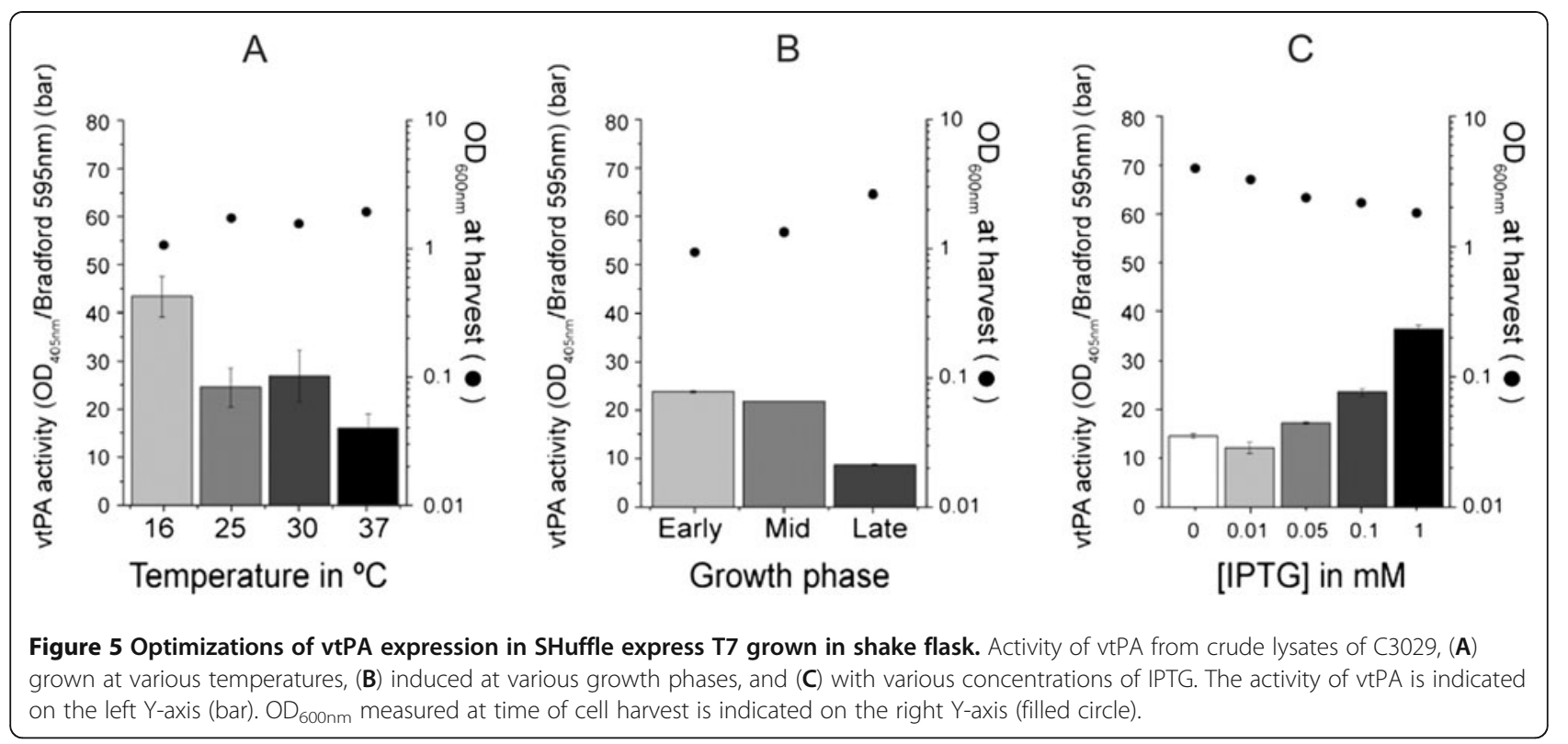

GroEL. As expected, protein solubility varied a great deal. Solubility ranged from $5 \%$ for poorly folding substrate proteins such as vtPA and urokinase to $95 \%$ for protein substrates that fold efficiently such as PhoA (Figure 6). These data highlight the fact that the solubility of a protein is highly dependent on the nature of the protein and high levels of soluble protein can be achieved when over-expressed in SHuffle cells.

\section{Co-expression of helper proteins can improve oxidative folding}

Folding of disulfide bonded eukaryotic proteins in a prokaryotic host is challenging. For any given protein, there may be one or more bottlenecks in its folding pathway that occur when the folding of the protein is decoupled from its native host environment. Reasons for inefficient folding are diverse and unique for each protein and may be due to: the lack of intrinsic folding properties of the protein (e.g. rate of translation governed by codon usage), the physical environment (e.g. folding in a specialized compartment) or the dependence on a set of chaperones dedicated to the folding of the nascent polypeptide in the native host. This problem is highlighted by the variation in the solubility of the proteins we expressed in SHuffle. To increase the capacity of SHuffle cells to fold a greater variety of disulfide bonded proteins, we co-expressed numerous "helper" proteins based on our assumption that they may alleviate a folding bottleneck that may exist for a given protein. We therefore chose our least soluble proteins (vtPA, urokinase and chitinase) as indicators of folding improvement, as we hypothesized that these proteins would allow the largest range of improvement. To facilitate improved folding of these proteins, we co-expressed 16 different helper proteins which could subdivided into three general categories: redox active, chaperone and oxidative stress. All of the

\section{His-tagged}

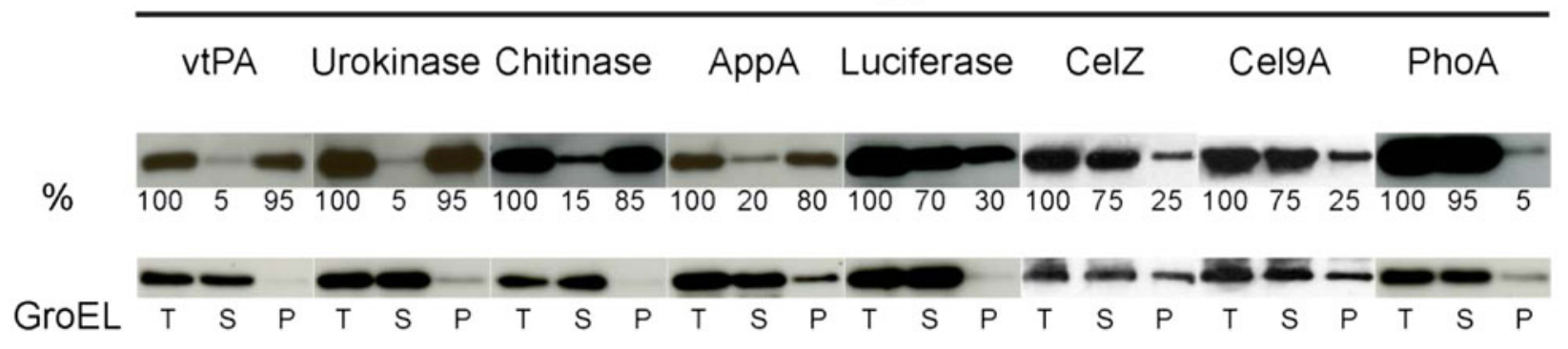

Figure 6 Solubility of proteins expressed with optimal conditions in SHuffle. Cells were lysed and total cells lysates (T) were separated into soluble (S) and pellet (P) fractions. Samples were analyzed using western blot with the appropriate antibody and percentages of solubility are indicated. Anti-GroEL antibody was used as loading control. 
helper genes were cloned into pBAD34 expression vector with a PACYC origin of replication, under the regulation of the arabinose promoter. A second set of C-terminally flag-tagged constructs were constructed in order to assess the expression levels of the helper proteins using western blots probed with anti-flag antibodies. Full length proteins were detected for all of the helper proteins except PDI, which could be detected upon longer exposure (Supplementary material Figure 3). SHuffle cells expressing vtPA, urokinase or chitinase along with one of the helper plasmids were grown under the optimal expression conditions discovered prior. Expression of the helper protein was induced in the beginning of growth by adding final concentration of $0.2 \%(\mathrm{w} / \mathrm{v})$ L-arabinose and the substrate protein was induced once the cells reached mid log growth phase. Enzymatic activities were measured and normalized to cells expressing vector alone (pBAD33). The results are summarized in Table 3. Overall, we found that co-expression of helper proteins dramatically improved the yield of vtPA (up to 11-fold) while only slightly improving the yields of urokinase and chitinase (less than 2-fold for the best helper). An in-depth description of these results is below.

\section{Redox active helpers}

It is possible that the mechanism of disulfide bond formation in the cytoplasm of SHuffle cells is not optimal

Table 3 Effects of co-expression of helper proteins on substrate protein activity

\begin{tabular}{|c|c|c|c|c|}
\hline & Helper & vtPA & Urokinase & Chitinase \\
\hline & pBAD33 & 1.00 & 1.00 & 1.00 \\
\hline \multirow{11}{*}{ Redox active Helpers } & cAaDsbC & 5.92 & 1.17 & 0.32 \\
\hline & cDsbc & 0.19 & 1.19 & 0.97 \\
\hline & $\operatorname{Tr} \times A_{C G P C}$ & 4.50 & 1.16 & 1.19 \\
\hline & $\operatorname{TrX} A_{C P Y C}$ & 9.83 & 1.05 & 0.85 \\
\hline & $\operatorname{Tr} x A_{C P H C}$ & 7.73 & 1.02 & 0.71 \\
\hline & cAaPDO & 3.31 & 0.58 & 0.76 \\
\hline & QSOX & 8.12 & 0.86 & 1.02 \\
\hline & PDI & 3.08 & 1.52 & $(1.58)$ \\
\hline & EUG1 & 5.43 & 1.31 & 1.24 \\
\hline & MPD1 & 4.88 & 1.10 & 1.42 \\
\hline & MPD2 & 8.91 & 1.37 & 1.18 \\
\hline \multirow{2}{*}{ Chaperone helpers } & MalE & 0.87 & 1.11 & 1.13 \\
\hline & HlpA (skp) & 6.97 & 1.16 & 0.53 \\
\hline \multirow{3}{*}{ Oxidative stress helpers } & KatG & $(11.81)$ & 0.90 & 1.05 \\
\hline & AhpC, AhpF & 5.69 & $(1.84)$ & 0.90 \\
\hline & $\mathrm{AhpC}^{*}, \mathrm{AhpF}$ & 4.29 & 1.30 & 1.08 \\
\hline
\end{tabular}

Brackets indicates the best fold improvements while bold are the following best fold improvements. for the correct folding of a given protein. There may not be sufficient disulfide bond isomerase (DsbC) for the abundance of overexpressed substrate proteins. To assess this, we expressed DsbC lacking its native signal peptide. No significant improvement in activity of urokinase and chitinase were detected upon increased levels cytoplasmic DsbC (Table 3), indicating that sufficient amounts of DsbC are expressed in SHuffle cells and that disulfide bond isomerization is not the folding bottleneck for these proteins. However, vtPA activity was reduced 5fold in SHuffle strains in comparison to isogenic strains lacking cytoplasmic DsbC (Table 3).

The role of thioredoxins in the formation of disulfide bonds within the $\operatorname{tr} x B$ suppressor strains has already been demonstrated [6]. Furthermore, co-expressing mutant thioredoxins with altered active sites has resulted in significant improvement in protein production [8]. We therefore chose the two mutant thioredoxins with altered active sites along with the wild type $(C G P C=w t$, $\mathrm{CPYC}=\mathrm{Grx1}, \quad \mathrm{CPHC}=\mathrm{DsbA})$ to assess whether coexpressing thioredoxins could assist in the formation of correctly oxidized substrates. Co-expression of thioredoxins increased the activity of vtPA up to 10-fold but did not result in any improvement in the case of urokinase and chitinase.

Protein disulfide isomerase (PDI) is an essential ER resident oxido-reductase involved in the oxidation and isomerization of disulfide bonded proteins in eukaryotes. In vitro it catalyzes the oxidative formation, reduction, or isomerization of disulfide bonds depending on the redox potential of the environment [42]. Expression of PDI in E. coli has already been demonstrated with mixed success. Co-expression of yeast PDI in the periplasm resulted in a $50 \%$ increase in the yield of tissue plasminogen activator (tPA), while rat PDI had no beneficial effect both in the periplasm and cytoplasm [43]. Due to this apparent substrate specificity of PDI's, we decided to coexpress various PDI homologs from Saccharomyces cerevisiae (PDI, EUG1, MPD1 and MPD2). Co-expression of the PDI homologs was the most successful class of helper proteins. In the case of urokinase and chitinase, PDI homologs were the best helper proteins while in the case of vtPA only one PDI homolog (MPD2) was second best helper protein (Table 3).

Sulfhydryl oxidases, such as human quiescin-sulfhydryl oxidase (QSOX) [44], can catalyze the formation of disulfide bonds through their FAD cofactor, resulting in the reduction of oxygen to hydrogen peroxide [45]. We chose QSOX as a helper protein, as co-expression of other sulfhydryl oxidases enhances production of disulfide bonded proteins in the cytoplasm of E. coli [28-30]. Although co-expression of QSOX increased vtPA activity 8 -fold, it had no positive influence on the expression of urokinase and chitinase (Table 3). 
Another candidate as a helper protein was the archeal cytoplasmic protein disulfide oxidoreductase (PDO) which can catalyze disulfide bond formation in vitro [46,47]. We chose the PDO from Aquifex aeolicus, as this species has been predicted to have one of the most oxidizing cytoplasms [48]. Co-expression of the A. aeolicus VF5 PDO did not result in any significant improvement in the yields of vtPA, urokinase or chitinase (Table 3).

\section{Chaperone helpers}

As a fusion protein, maltose binding protein (MBP) promotes folding and increases the solubility of its fused cargo [49]. We co-expressed MBP as a helper protein but did not observe any significant improvement in the yields of vtPA, urokinase and chitinase. This may be due to the observation that MBP is most successful at increasing solubility when fused N-terminally [50], indicating that MBP may need to act on the elongating polypeptide and may not act as a chaperone post-translationally when not fused. Another periplasmic chaperone we expressed within the cytoplasm of SHuffle was the "seventeen kilo Dalton protein" (Skp) known to have a broad range of interacting substrates [51]. Cytoplasmic co-expression of Skp improves the folding of certain eukaryotic proteins [52]. However, no positive effects on folding of our test proteins were observed when Skp was co-expressed (Table 3).

\section{Oxidative stress helpers}

SHuffle cells lack trxB and gor and cannot efficiently reduce oxidized proteins. This result in the buildup of oxidized inactive proteins, which induces a general oxidative stress response, mediated by the transcriptional factors OxyR and the SoxRS regulon [53,54]. In addition, $\mathrm{AhpC}^{*}$ has lost its function as a peroxidase resulting in the accumulation of hydrogen peroxide. This can cause oxidative damage to proteins and may diminish cell viability, which in turn, may lower the yield of recombinant protein production. Under such conditions, the expression of the catalase gene katG, which scavenges and removes hydrogen peroxide and the peroxidase AhpC is highly up regulated [55]. However, native defense mechanisms may not be sufficient, as SHuffle cells have three of its reductive pathways disrupted (glutathione, thioredoxin and peroxiredoxin pathways). We therefore chose KatG and AhpCF and the peroxidase deficient mutant $\mathrm{AhpC}^{*} \mathrm{~F}$ as candidate helper proteins to combat oxidative stress. Expression of katG resulted in 12-fold increase in the activity of vtPA, making it the best helper protein, while expression of AhpCF and $\mathrm{AhpC}$ F had modest effects on vtPA. In the case of urokinase, co-expression of either AhpCF or AhpC ${ }^{*} \mathrm{~F}$ resulted in the best improvements in activity. In the case of chitinase, none of these helpers had any effect (Table 3). Taken together, these results further highlight the protein specific nature of protein folding and the lack of predictability in deciding which molecular chaperone system will improve protein solubility [56].

\section{Discussion}

In this manuscript we present a novel $E$. coli strain based on the $\operatorname{tr} x B$ gor suppressor strain SMG96. We further engineered into its chromosome a $d s b C$ gene lacking its signal sequence, under the regulation of the strong ribosomal promoter $r r n B$. These strains were engineered both in E.coli K12 and B strain backgrounds. A detailed characterization of the SHuffle strains along with parameters involved in protein production at bench-scale (non-high throughput) was investigated.

To expand our understanding of the mechanism of disulfide bond formation within SHuffle strains, we investigated the redox state of cytoplasmic DsbC. We showed that the majority of cytoplasmic DsbC is in its hemireduced state, which is essential for its disulfide bond isomerase activity. However, oxidized DsbC species were also detected when expressed within the oxidizing cytoplasm, which could result in DsbC directly oxidizing reduced substrates. This is not surprising, as mutant DsbB which have gained the ability to oxidize DsbC are in turn capable of oxidizing proteins in the periplasm [57]. Oxidized DsbC species may not always be beneficial to the folding of reduced proteins which require disulfide bonds. This may explain the drop in activity observed for Gaussia luciferase when expressed in cells with cytoplasmic DsbC. Similar observations were made when expressing parathyroid hormone in $\operatorname{trx} B$ gor strains [58]. In this study, co-expression of cytoplasmic DsbC had no positive influence in vivo, but did dramatically reduce the amount of misfolded species when DsbC was co-incubated in the presence of oxidized and reduced glutathione.

E. coli B strains such as BL21 are the preferred host strain for protein expression as generally give higher yields for the large majority of proteins. Some of the reasons for this may be that, unlike its K12 cousin, it has not been subjected to extensive domestication for the purpose of DNA manipulation [59], and it lacks the cytoplasmic protease lon known to play a key role in protein quality control [60]. Similarly, when we compared the expression of three proteins in SHuffle K12 vs. SHuffle B strains, we consistently observed higher yields in the B strain backgrounds. However, we also observed differences between the two strains at the level of redox states of proteins. Unlike in SHuffle K12, a fraction of periplasmic DsbC was observed to be in its reduced state in the SHuffle B strain. Further redox differences were observed in the ahpC mutations between the two strains. While SHuffle $\mathrm{K} 12 \operatorname{ahpC}$ gene has the triplet TTC codon expansion, SHuffle B ahpC gene has the triplet codon contraction, lacking one of the three TTC codons. These differences 
highlight the distinct biological differences between the two SHuffle strains and require detailed studies to elucidate their biological roles.

To define conditions critical for the folding and correct formation of disulfide bonds, we tested the impact of the three most commonly manipulated physical parameters; temperature, time and strength of induction. We consistently observed that growth temperatures had the most profound impact on improving protein production in SHuffle cells. This may be due to the fact that SHuffle cells are under oxidative stress, and the resulting detrimental effects may be compounded by high metabolic activity during growth at high temperatures such as $37^{\circ} \mathrm{C}$. This hypothesis is supported by the observation that over-expression of poorly folding proteins such as vtPA at $37^{\circ} \mathrm{C}$ in SHuffle cells is toxic (data not shown).

We observed very efficient production of proteins to high yields when SHuffle cells were grown overnight in Magic Media, reaching final yields of $400 \mathrm{mg} / \mathrm{l}$ in the case of a cellulase (with a single disulfide bond). To validate the role of the media, we produced vtPA in Magic Media and observed a 6 fold increase in the final yields compared to standard expression conditions using IPTG as an inducer. This form of protein expression in SHuffle cells may indeed be optimal, even though the mechanism of expression is not clear. Although the exact composition of Magic Media is not disclosed, it is designed to be used for the auto-expression of proteins under the control of the lac promoter. The principle of autoexpression is based on diauxic regulation where glucose is the preferred carbon source which results in the repression of the lac promoter and upon its consumption, cells switch to growth on lactose which results in the induction of the lac promoter [39]. However, $\beta$-galactosidase activity is needed to convert lactose to allolactose, the natural inducer of the lactose operon [61]. In the case of the SHuffle B T7 cells, the T7 RNA polymerase gene 1 is inserted into the lac $Z$ gene, rendering it inactive. Thus, another mechanism of expression other than autoinduction must be occurring, which is why we termed this form of expression "autoexpression" instead of autoinduction.

In this study, we focused on improving folding of target substrate proteins by manipulating the strain and the conditions of expression. However, for optimal expression of proteins, many other parameters must be manipulated. For example, all proteins which require disulfide bonds for their folding will be secreted to compartments where disulfide bond formation can occur. Thus, they will all have some sort of a signal sequence at their N-terminus. However, to express these proteins in the cytoplasm, a signal sequenceless version of the target protein must be expressed. Removal of the 5' signal sequence will alter the composition and structure of the mRNA, which is known to play a key role in the expression level of the target protein [62]. One remedy to this potential problem is to fuse the target protein to the carboxyl terminal of MBP, which is known to enhance solubility and can be proteolytically removed post production [49]. Otherwise, using the appropriate expression vector with the optimal promoter, codon usage and ribosome binding site need to be considered for optimal expression of the target protein.

Since bottlenecks in the folding pathway of any given protein are specific to that protein, we explored whether we could increase protein yield by co-expressing various helper proteins. We chose a subset of helper proteins based on either prior experimentation which has shown their utility, or in assumptions based on the helper proteins properties. Redox-active helper proteins had the biggest effect. Co-expression of mutant thioredoxins and PDI homologs were the most successful class of helper proteins. Surprisingly, co-expression of the catalase $k a t G$ improved the activity of vtPA 10-fold. This observation supports the notion that the SHuffle cells are under oxidative stress and boosting the cell's defenses against oxidative damage can increase the capacity of the cells to produce correctly folded disulfide bonded proteins. However, the decrease in vtPA activity when additional DsbC was expressed from the helper plasmid accentuates the fact that, for each individual protein, there can be an optimum level of a redox helper, with a decrease in activity at amounts higher or lower than that optimum. A similar decrease in activity was observed in the case of periplasmic expression of vtPA [17]. Overexpression of periplasmic DsbC resulted in loss in vtPA activity and eventually resulted loss of viability. The authors attributed the loss in viability to a dramatic reduction in the oxygen uptake rate when DsbC was over-expressed [17]. It is plausible that a similar interaction is occurring in the cytoplasm. This drop in activity was not observed when the putative disulfide bond isomerase from Aquifex aeolicus (cAaDsbC) was co-expressed. This difference highlights the protein specificities that govern the interaction between the oxido-reductase and its substrate protein.

Expression of proteins in the cytoplasm instead of in the periplasm is of great advantage. Not only does one avoid the complication of having to secrete the target substrate, the periplasm is devoid of ATP, has only a few ATP-independent chaperones, and is only $\sim 20 \%$ of the volume of cytoplasm [63]. The advantage of cytoplasmic expression was observed in the case of vtPA, which had two fold increase in activity when expressed in the cytoplasm [8]. Similarly, we observed a 7 fold increase in the activity of an $\alpha 1,3$ Galactosidase from Xanthomonas manihotis having a single disulfide bond, when expressed in the cytoplasm instead of the periplasm (data not shown).

Although cytoplasmic expression may improve the activity of certain proteins, cytoplasmic disulfide bond 
formation may sometimes be detrimental to certain biological processes. For example, cytoplasmic assembly of the $E$. coli phage M13 appears to be problematic, as SHuffle strains were incapable of forming infective phage (data not shown). In addition, SHuffle cells grown in minimal media under high dissolved oxygen rates showed poor growth when glycerol was the sole carbon source (data not shown). This may be due to altered redox state of SHuffle cells' metabalome. For example, the $c y d A B$ operon, which is under the regulation of the ArcAB two component system [64], shows a delayed response in transcriptional activity when shifting from aerobiosis to anerobiosis in SHuffle cells (data not shown). This is most likely due to the silencing of ArcB kinase activity by the oxidation of its cytoplasmic redoxactive cysteine residues [65]. These observations highlight our current lack of understanding of the redox biology of SHuffle cells, with many important questions remaining unanswered. How do SHuffle cells cope with oxidizing and reducing conditions within cytoplasm? Which reductases are involved in the oxidation of substrate proteins? What is the role of cytoplasmic oxidized DsbC in disulfide bond formation? How do SHuffle cells perform in high density fermentations? Proteomic and mass spectrometric approaches to address these questions are now in progress.

The SHuffle strains and the expression conditions presented in this report represent the first detailed analysis of the conditions required for efficient cytoplasmic expression and folding of disulfide bonded proteins. The results should allow the expression of previously inaccessible production of proteins in $E$. coli. These SHuffle strains greatly expand the cell biologists toolkit by enabling the use of bacterial production in place of more cumbersome eukaryotic expression systems.

\section{Conclusions}

We have demonstrated the value in engineering an $E$. coli $\operatorname{trx} B$ gor suppressor strain which expresses active cytoplasmic DsbC. We found that temperature is of paramount importance and should be optimized for the optimal expression of a substrate protein. Autoexpression of proteins using Magic Media was also very helpful in improving yield. We found several intriguing redox related differences between the E. coli $\mathrm{B}$ and K12 versions of this strain and showed that the $E$. coli $B$ version of SHuffle strains were superior to its K12 counterpart. Further improvements were made by coexpressing various helper proteins. These SHuffle strains along with the knowledge gained regarding their use will be of great use to the protein expression community.

\section{Methods}

\section{Bacterial strains, media, and chemicals}

Bacterial strains and plasmids were constructed by using standard genetic procedures. List of strains used is summarized in supplementary materials Table 1. SHuffle K12 cells were engineered based on the $\operatorname{tr} x B$ gor suppressor SMG96 [32]. A signal sequenceless $d s b C$ construct under the regulation of $r r n B$ promoter was integrated into SMG96 using the lambda inch method [66]. SHuffle B strains are based on NEB express cells (C2523) and were constructed using the dithiothreitol (DTT) filter disk method, as described prior [32]. While the commercial names of the SHuffle strains are SHuffle (for the K12 versions) and SHuffle express (for the $B$ versions), we will refer to these strains as SHuffle K12 or SHuffle B for the purposes of clarity. Further versions were engineered by integrating the T7 gene 1 which encodes for the T7 RNA polymerase into lacZ, allowing for expression of genes under the regulation of the $\mathrm{T} 7$ promoter. A list of plasmids used in this study along with their construction is summarized in supplementary materials Table 2 and 3. Synthetic genes were purchased from Genescript (www. genscript.com). Cells were grown in Rich Media (10 g/L Tryptone, $5 \mathrm{~g} / \mathrm{L}$ Yeast Extract, $5 \mathrm{~g} / \mathrm{L} \mathrm{NaCl}, \mathrm{NaOH}$ to $\mathrm{pH}$ 7.2) or in Magic Media (Invitrogen cat\# K6803).

\section{Optimization of protein expression}

Three parameters were optimized sequentially in the following order; temperature of growth, time of induction and strength of induction. All experiments were conducted in duplicate samples. Initially, $-80^{\circ} \mathrm{C}$ strain stocks were used to inoculate $5 \mathrm{ml}$ rich media with the appropriate antibiotics $(200 \mu \mathrm{g} / \mathrm{ml}$ ampicillin, $40 \mu \mathrm{g} / \mathrm{ml}$ Kanamycin or $10 \mu \mathrm{g} / \mathrm{ml}$ Chloramphenicol). The following day, $25 \mathrm{ml}$ of rich media in $125 \mathrm{ml}$ shaker flask supplemented with antibiotics were inoculated with $250 \mu \mathrm{l}$ $\left(1 / 100^{\text {th }}\right)$ of overnights and grown at $30^{\circ} \mathrm{C}$ for 3 hours until mid-log phase, set as default time of induction for the first step of optimization. The cultures were induced with $1 \mathrm{mM}$ isopropyl- $\beta$-D-thiogalactopyranoside (IPTG) set as the default concentration of IPTG and temperature was shifted to $16^{\circ} \mathrm{C}, 25^{\circ} \mathrm{C}, 30^{\circ} \mathrm{C}$ or $37^{\circ} \mathrm{C}$ and grown respectively overnight for low temperatures $\left(16^{\circ} \mathrm{C}\right.$ or $\left.25^{\circ} \mathrm{C}\right)$ or another $7 \mathrm{~h}$ for higher temperatures $\left(30^{\circ} \mathrm{C}\right.$ or $37^{\circ} \mathrm{C}$ ). Cells were harvested by centrifugation, lysed by sonication and samples were standardized to equal amounts of protein using Bradford reagent. The optimal temperature of protein expression was determined by measurement of enzymatic activities of crude lysates with appropriate enzymatic tests. The second step of optimization was focused on the time of induction using the optimal temperature from the previous step. Cultures were inoculated as previously described. Cultures were induced either at the time of inoculation (Early induction) 
or at mid-log phase (Mid induction) or at late-log phase of growth (Late induction). Downstream processes were the same as previously described. Strength of induction was tested by inducing cultures at various IPTG concentrations from $0 \mathrm{mM}$ to $1 \mathrm{mM}$ IPTG. Cells were inoculated as previously described and grown at $30^{\circ} \mathrm{C}$ until optimal time of induction. Various amount of IPTG were added and cultures were incubated at optimal temperature of protein production. Enzymatic activities were measured from crude lysates as previously described.

\section{Co-expression of helper proteins}

Cultures were grown in rich media supplemented with $0.2 \%$ L-arabinose (Sigma Aldrich A3256) to induce coexpression of helper proteins and grown with optimal growth and induction conditions as previously described. Appropriate enzymatic activities were measured from crude lysates using protocol described previously.

\section{Autoexpression}

Cultures were inoculated and grown in Magic Media (Invitrogen cat\# K6803) until reaching optimal time of induction. The temperature was shifted to the optimal temperature of production.

\section{Protein activity assays \\ Urokinase assay}

Urokinase activity was quantified using a coupled reaction in a microtiter plate. $50 \mu \mathrm{l}$ of soluble protein were

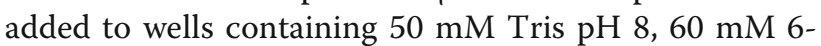
aminohexanoic acid (Sigma Aldrich, cat\# 07260), $0.1 \mathrm{mg} / \mathrm{ml}$ Bovine Plasminogen (American Diagnostica, cat\# 416) and 0.4 mM Spectrozyme PL (American Diagnostica, cat\# 251) to a final volume of $150 \mu \mathrm{l}$. The plate was incubated at $37^{\circ} \mathrm{C}$ and absorbance at $405 \mathrm{~nm}$ was measured for 2 or $3 \mathrm{~h}$ until reaching plateau. Activity is directly proportional to $\mathrm{A}_{405 \mathrm{~nm}}$ at linear range standardized to protein amount at $\mathrm{A}_{595 \mathrm{~nm}}$ using Bradford reagent.

\section{tPA assay}

Plasminogen activation was quantified using a coupled reaction in a microtiter plate. $50 \mu \mathrm{l}$ of soluble protein were added to wells containing $50 \mathrm{mM}$ Tris- $\mathrm{HCl}$ (pH7.4), $0.01 \%$ Tween $80,0.04 \mathrm{mg} / \mathrm{ml}$ human glu-plasminogen (American Diagnostica, cat \# 400), and 0.4 mM Spectrozyme PL (American Diagnostica, cat \# 251), to a $250 \mu \mathrm{l}$ final volume. The plate was incubated at $37^{\circ} \mathrm{C}$ and absorbance at $405 \mathrm{~nm}$ was measured after 2 or $3 \mathrm{~h}$ until reaching plateau. Activity is directly proportional to $\mathrm{A}_{405 \mathrm{~nm}}$ at linear range standardized to protein amount at $A_{595 \mathrm{~nm}}$ using Bradford reagent [8].

\section{Gluc assay}

The Gluc activity was quantified using Gaussia Luciferase Assay Kit E3300L (New England Biolabs, cat\# E3300).

\section{PhoA assay}

The PhoA activity was quantified using chromogenic reaction in a clear bottom microtiter plate. $20 \mu \mathrm{l}$ of soluble protein were added to wells containing $180 \mu \mathrm{l}$ of $20 \mathrm{mM}$ para-nitrophenyl phosphate (pNPP, Sigma Aldrich, cat \# N4645), $1 \mathrm{M}$ Tris $\mathrm{pH} 8,1 \mathrm{mM}$ ZnAc. The plate was incubated at $37^{\circ} \mathrm{C}$ and absorbance at $410 \mathrm{~nm}$ was measured for 20 minutes. Activity is directly proportional to $\mathrm{A}_{410 \mathrm{~nm}}$ at linear range standardized to protein amount at $\mathrm{A}_{595 \mathrm{~nm}}$ using Bradford reagent.

\section{AppA assay}

AppA activity was quantified as described earlier [12] with slight modifications. Assays were performed in microtiter plates with $20 \mu \mathrm{l}$ of appropriately diluted soluble protein. Reaction was stopped with $50 \mu \mathrm{l} 5 \mathrm{M} \mathrm{NaOH}$. AppA activity was measured at $\mathrm{A}_{410 \mathrm{~nm}}$ and standardized to protein amount at $A_{595 n m}$ using Bradford reagent.

\section{Chitinase assay}

Chitinase activity was quantified by fluorometric assay as follows. In microtiter white opaque plate, a serial dilution (1:4 to $1: 256)$ of $50 \mu \mathrm{l}$ of soluble protein was added to wells containing $20 \mathrm{mM} \mathrm{NaPO} 4,200 \mathrm{mM} \mathrm{NaCl}, 1 \mathrm{mM}$ EDTA, 20uM 4-methylimbelliferyl-N, N', N"-triacyl-Bchitotrioside (stock in 100\% DMSO) (Calbiochem) to $200 \mu \mathrm{l}$ final volume. The plate was incubated at $25^{\circ} \mathrm{C}$ and fluorescence (Excitation $\mathrm{A}_{320 \mathrm{~nm}}$, Emission $\mathrm{A}_{460 \mathrm{~nm}}$ ) was measured 2 to $3 \mathrm{~h}$. Activity is directly proportional at linear range to $A_{460 n m}$ standardized to protein amount at $A_{595 \mathrm{~nm}}$ using Bradford reagent.

\section{CelZ assay}

Activity was measured by incubation of known quantities of celZ with the chromophore p-nitrophenylcellobioside at $50^{\circ} \mathrm{C}$, in $50 \mathrm{mM}$ HEPES, pH 7.2 for $30-60^{\prime}$ in $50 \mu \mathrm{L}$ volumes. Reactions were stopped and color developed by the addition of $12.5 \mu \mathrm{L} 10 \% \mathrm{w} / \mathrm{v} \mathrm{NaCO} 3$ and read at $410 \mathrm{~nm}$.

\section{Cel9A assay}

Activity was measured by digests of carboxymethylcellulose (CMC). Reactions were carried out with known quantities of protein in $50 \mu \mathrm{L}$ volumes of $1 \% \mathrm{w} / \mathrm{v} \mathrm{CMC}$ (med. viscosity, Fluka) for $30-60^{\prime}$ at $50^{\circ} \mathrm{C}$ in $50 \mathrm{mM}$ HEPES, pH 7.2. Reducing sugars liberated were measured using the 3,5-dinitrosalysilic acid (DNS) method with a panel of glucose standards, read at $540 \mathrm{~nm}$. Activity is expressed in glucose equivalents. 


\section{Protein purification vtPA and gluc}

Cells expressing either His tagged vtPA, or His tagged GLuc from various plasmids were grown with shaking in $500 \mathrm{~mL}$ Rich Medium supplemented with appropriate antibiotics. Optimal amount of IPTG was added after optimal time of growth at $30^{\circ} \mathrm{C}$ and the cultures were grown for an additional time at optimal temperature. Cells were harvested by centrifugation (12000 rpm, $20 \mathrm{~min}, 4^{\circ} \mathrm{C}$ ) and resuspended in Phosphate Buffer (20 mM Phosphate Buffer, $500 \mathrm{mM} \mathrm{NaCl}, 20 \mathrm{mM}$ Imidazole), and lysed using sonication $8 \times 30$ s. The insoluble fractions were removed be centrifugation (14000 rpm, $30 \mathrm{~min}, 4^{\circ} \mathrm{C}$ ). Protein was purified using a HiTrap IMAC FF $1 \mathrm{~mL}$ column (GE Healthcare), eluting with $1 \mathrm{M}$ Imidazole. Fractions containing protein are pooled, dialyzed in storage buffer $(200 \mathrm{mM} \mathrm{NaCl}, 20 \mathrm{mM}$ Tris $\mathrm{HCl}$ pH 7.5, 1 mM EDTA, 0.1\% Triton X-100, 50\% Glycerol), and loaded on a SDS-PAGE gel. Protein amount was determined by Bradford assay using BSA as standard. Corresponding assay were performed on the purified samples as described before.

\section{Chitinase, AppA and PhoA}

Cells expressing His tagged Chitinase, AppA or PhoA from various plasmids were grown and harvested as described before. The pellet was resuspended in Tris binding buffer $(20 \mathrm{mM}$ Tris $\mathrm{pH} 8,300 \mathrm{mM} \mathrm{NaCl}$, $10 \mathrm{mM}$ Imidazole) and purification was performed as described before.

\section{Cellulase purification}

Individual colonies were picked in duplicate and used to inoculate $5 \mathrm{~mL} \mathrm{LB}$-carb starter cultures at $37^{\circ} \mathrm{C}$. Starter cultures were measured for growth by $\mathrm{OD}_{600 \mathrm{~nm}}$ and used to inoculate either 50 or $100 \mathrm{~mL}$ cultures of Magic Media $+100 \mu \mathrm{g} / \mathrm{mL}$ carbenicillin in 250 or $500 \mathrm{~mL}$ (respectively) baffled flasks to a density of 0.05 . Cells were grown at $37^{\circ} \mathrm{C}$ until $\mathrm{OD}_{600 \mathrm{~nm}}$ reached 1.0 at which time, temperature was dropped to $22-25^{\circ} \mathrm{C}$ and cultures were grown for a total of $24 \mathrm{~h}$, and harvested when 2 consecutive $\mathrm{OD}_{600 \mathrm{~nm}}$ measurements (taken at $0.5 \mathrm{~h}$ intervals) showed no increase in density. Cells were immediately put on ice and transferred to cold $50 \mathrm{~mL}$ conical bottom tubes, then centrifuged at $4^{\circ} \mathrm{C}$ for $30^{\prime}$ at $3500 \mathrm{rpm}$. Cells were resuspended in $10 \mathrm{~mL}$ lysis buffer: $1 \times \mathrm{xPBS}$ (teknova), PMSF, leupeptin, pepstatin, $1 \mathrm{mg} / \mathrm{mL}$ lysozyme (egg white, Sigma), $1 \mathrm{U} / \mathrm{mL}$ DNase I. Pellets were disrupted by sonicating for 5 minutes (30s on, 30s off) on ice. A sample was taken for T. Disrupted cells were spun down at $3500 \mathrm{rpm}$ for $30^{\prime}$ at $4^{\circ} \mathrm{C}$. $4 \mathrm{~mL}$ fractions of the supernatant were diluted with $2 \mathrm{x}$ binding buffer (40 mM imidazole, $1 \mathrm{M} \mathrm{NaCl}, 0.1 \mathrm{M}$ phosphate, $\mathrm{pH} 7.5$ ) and centrifuged cold to remove new precipitations.
$8 \mathrm{~mL}$ volumes were loaded onto a $1 \mathrm{~mL}$ HisTrap FF column, washed with 12 Column Volumes (CV) binding buffer, and eluted on a 20-140 mM imidazole gradient, collected in $5 \mathrm{~mL}$ fractions (Bio-Rad Biologic LP + BioFrac). Purified proteins were quantitated by the Bradford method (Bio-Rad kit). Specific activity was determined using the corresponding enzymatic assay.

\section{Protein sample analysis AMS alkylation}

Cells were grown in rich media supplemented with antibiotics until reaching late log phase of growth $(5 \mathrm{~h})$. OD600nm was measured and cultures were diluted to the lowest OD. 3 samples of $1 \mathrm{ml}$ culture were incubated on ice for at least 15 minutes with $15 \%$ trichloroacetic acid (TCA). The supernatant was discarded after centrifuging $10 \mathrm{~min}$ at maximum speed. The pellets were washed with $500 \mu \mathrm{l}$ Acetone, mixed by vortex and centrifuged for $5 \mathrm{~min}$ at maximum speed. The pellets were air dried and resuspended in $150 \mu \mathrm{l}$ of either loading buffer (1X Loading buffer, $1 \%$ SDS, $0.1 \mathrm{M}$ Tris pH8), 4-acetamido-4'maleimidylstilbene-2,2'-disulfonic acid (AMS) buffer (15 mM AMS, 1X Loading buffer, 1\% SDS, 0.1 Tris pH8) or DTT buffer (100 mM DTT, 1X Loading buffer, 1\% SDS, 0.1 Tris pH8). The samples were boiled for 20 minutes at $95^{\circ} \mathrm{C}$ and incubated at $4^{\circ} \mathrm{C}$ overnight. Samples resuspended in DTT buffer were incubated on ice for at least 15 minutes with 15\% TCA and centrifuged for 10 minutes at maximum speed. The pellet was washed with $500 \mu$ l Acetone and air dried. The pellet was resuspended in AMS buffer. $15 \mu$ of samples was loaded on a SDS-PAGE gel and probed with appropriate antibody.

\section{Western blot}

Samples were diluted 1:3 in 1x Loading Buffer (New England Biolabs, B7709) supplemented with 1x DTT. Samples were loaded on Daichi pre-cast 10/20 gels (Cosmo Bio Co. LTD, cat\# 414893) and run for $1 \mathrm{~h}$ at $30 \mathrm{~mA}$ per gel. Proteins were transferred on PVDF (IPVH00010 Milipore) membranes using wet transfer methods for $1.5 \mathrm{~h}$ at $500 \mathrm{~mA}$. Membrane was blocked with 5\% Dry Milk (BioRad, 170-6404XTU) in PBS (Gibco, AM9625) for $1 \mathrm{~h}$ at room temperature or overnight at $4^{\circ} \mathrm{C}$. Membrane was washed $3 \times 5 \mathrm{~min}$ in PBS, Tween $0.05 \%$ and incubated with appropriate antibody diluted in PBS-T Dry Milk $1 \%$ for $1 \mathrm{~h}$ at room temperature. After washing the membrane as described previously the membrane was incubated with secondary antibody if needed diluted in PBST for $1 \mathrm{~h}$ at room temperature. After washing as described above the membrane was poured with 20X LumiGLO ${ }^{\bullet}$ Reagent and 20X Peroxide (\#7003 Cell signaling technology) for $30 \mathrm{~s}$. The signal intensity was measured. 


\section{Additional file}

Additional file 1: Figure 1. Growth of SHuffle and wt E. coli at $30^{\circ} \mathrm{C}$. Growth of various strains monitored for $30 \mathrm{hrs}$ at $30^{\circ} \mathrm{C}$. Time point of mid (solid arrow) and late (dotted arrow) induction are shown. (A) Growth curves of K12 strains. (B) Growth curves of B strains $[67,68]$.

\section{Competing interests}

$\mathrm{MB}$ and PR are owners of New England Biolabs Stock.

\section{Acknowledgements}

We would like to thank the following people for their generous gifts and sharing of data; the members of the Beckwith lab for strains and constructs, Lloyd Ruddock for vtPA, PhoA and AppA constructs, Carolyn Sevier for PDI homologs, Colin Thorpe for QSOX, Elizabeth McLeod for the alphaglycosidase data, Dimitris Georgellis for the ArCAB data and Rachel Dutton for the suggestion of AaDsbC. We thank Melanie Berkmen for comments on the manuscript.

\section{Author details}

${ }^{1}$ New England Biolabs, Ipswich, MA 01938, USA. ${ }^{2}$ Allopartis Biotechnologies, San Francisco, CA 94158, USA. ${ }^{3}$ QB3-MacroLab, University of California, Berkeley, CA 94720, USA. ${ }^{4}$ Bradley University, Peoria, IL 61625, USA. ${ }^{5} \mathrm{New}$ England Biolabs, 240 County road, Ipswich, MA 01938, USA.

\section{Authors' contributions}

$J$ conducted most of the experiments, CE and CJ conducted the cellulase studies, MF constructed the SHuffle B strains, PR helped with the protein purification and $\mathrm{MB}$ designed and wrote the manuscript. All authors read and approved the final manuscript.

Received: 15 November 2011 Accepted: 8 May 2012 Published: 8 May 2012

\section{References}

1. Wong JW, Ho SY, Hogg PJ: Disulfide bond acquisition through eukaryotic protein evolution. Mol Biol Evol 2010, 28: 327-334.

2. Reuters: The therapeutic proteins outlook to 2007: An analysis of leading products and late-stage pipeline developments. Reuters Business Insight. London, UK, 2003.

3. Bardwell JC, McGovern K, Beckwith J: Identification of a protein required for disulfide bond formation in vivo. Cell 1991, 67:581-589.

4. Weissman JS, Kim PS: Efficient catalysis of disulphide bond rearrangements by protein disulphide isomerase. Nature 1993, 365:185188.

5. Derman Al, Prinz WA, Belin D, Beckwith J: Mutations that allow disulfide bond formation in the cytoplasm of Escherichia coli. Science 1993, 262:1744-1747.

6. Stewart EJ, Aslund F, Beckwith J: Disulfide bond formation in the Escherichia coli cytoplasm: an in vivo role reversal for the thioredoxins. EMBO J 1998, 17:5543-5550.

7. Ritz D, Lim J, Reynolds CM, Poole LB, Beckwith J: Conversion of a peroxiredoxin into a disulfide reductase by a triplet repeat expansion. Science 2001, 294:158-160.

8. Bessette $\mathrm{PH}$, Aslund F, Beckwith J, Georgiou G: Efficient folding of protein with multiple disulfide bonds in the Escherichia coli cytoplasm. Proc Natl Acad Sci U S A 1999, 96:13703-13708.

9. Levy R, Weiss R, Chen G, Iverson BL, Georgiou G: Production of correctly folded Fab antibody fragment in the cytoplasm of Escherichia coli trxB gor mutants via the coexpression of molecular chaperones. Protein Expr Purif 2001, 23:338-347.

10. Collet JF, Messens J: Structure, function, and mechanism of thioredoxin proteins. Antioxid Redox Signal 2010, 13:1205-1216.

11. Devi VS, Mittl PR: Monitoring the disulfide bond formation of a cysteinerich repeat protein from Helicobacter pylori in the periplasm of Escherichia coli. Curr Microbiol 2011, 62:903-907.

12. Berkmen M, Boyd D, Beckwith J: The nonconsecutive disulfide bond of Escherichia coli phytase (AppA) renders it dependent on the proteindisulfide isomerase, DsbC. J Biol Chem 2005, 280:11387-11394.
13. Shevchik VE, Condemine G, Robert-Baudouy J: Characterization of DsbC, a periplasmic protein of Erwinia chrysanthemi and Escherichia coli with disulfide isomerase activity. EMBO J 1994, 13:2007-2012.

14. Missiakas D, Georgopoulos C, Raina S: The Escherichia coli dsbC (xprA) gene encodes a periplasmic protein involved in disulfide bond formation. EMBO J 1994, 13:2013-2020.

15. McCarthy AA, Haebel PW, Torronen A, Rybin V, Baker EN, Metcalf P: Crystal structure of the protein disulfide bond isomerase, DsbC, from Escherichia coli. Nat Struct Biol 2000, 7:196-199.

16. Chen J, Song JL, Zhang S, Wang Y, Cui DF, Wang CC: Chaperone activity of DsbC. J Biol Chem 1999, 274:19601-19605.

17. Qiu J, Swartz JR, Georgiou G: Expression of active human tissue-type plasminogen activator in Escherichia coli. Appl Environ Microbiol 1998, 64:4891-4896

18. Kurokawa $Y$, Yanagi H, Yura T: Overproduction of bacterial protein disulfide isomerase ( $\mathrm{DsbC}$ ) and its modulator $(\mathrm{DsbD})$ markedly enhances periplasmic production of human nerve growth factor in Escherichia coli. J Biol Chem 2001, 276:14393-14399.

19. Jurado P, Ritz D, Beckwith J, de Lorenzo V, Fernandez LA: Production of functional single-chain Fv antibodies in the cytoplasm of Escherichia coli. J Mol Biol 2002, 320:1-10

20. Yuan S, Duan H, Liu C, Liu X, Liu T, Tao H, Zhang Z: The role of thioredoxin and disulfide isomerase in the expression of the snake venom thrombinlike enzyme calobin in Escherichia coli BL21 (DE3). Protein Expr Purif 2004 38:51-60.

21. Yang J, Kanter G, Voloshin A, Levy R, Swartz JR: Expression of active murine granulocyte-macrophage colony-stimulating factor in an Escherichia coli cell-free system. Biotechnol Prog 2004, 20:1689-1696.

22. Zawada JF, Yin G, Steiner AR, Yang J, Naresh A, Roy SM, Gold DS, Heinsohn HG, Murray CJ: Microscale to manufacturing scale-up of cell-free cytokine production-a new approach for shortening protein production development timelines. Biotechnol Bioeng 2011, 108:1570-1578.

23. Gurmu D, Lu J, Johnson KA, Nordlund P, Holmgren A, Erlandsen H: The crystal structure of the protein YhaK from Escherichia coli reveals a new subclass of redox sensitive enterobacterial bicupins. Proteins 2009, 74:18-31.

24. Choi H, Kim S, Mukhopadhyay P, Cho S, Woo J, Storz G, Ryu SE: Structural basis of the redox switch in the OxyR transcription factor. Cell 2001, 105:103-113.

25. Locker JK, Griffiths G: An unconventional role for cytoplasmic disulfide bonds in vaccinia virus proteins. J Cell Biol 1999, 144:267-279.

26. Ortenberg R, Gon S, Porat A, Beckwith J: Interactions of glutaredoxins, ribonucleotide reductase, and components of the DNA replication system of Escherichia coli. Proc Natl Acad Sci U S A 2004, 101:7439-7444.

27. Bessette PH, Qiu J, Bardwell JC, Swartz JR, Georgiou G: Effect of sequences of the active-site dipeptides of DsbA and DsbC on in vivo folding of multidisulfide proteins in Escherichia coli. J Bacteriol 2001, 183:980-988.

28. Nguyen VD, Hatahet F, Salo KE, Enlund E, Zhang C, Ruddock LW: Pre-expression of a sulfhydryl oxidase significantly increases the yields of eukaryotic disulfide bond containing proteins expressed in the cytoplasm of E.coli. Microb Cell Fact 2011, 10:1.

29. Hatahet F, Nguyen VD, Salo KE, Ruddock LW: Disruption of reducing pathways is not essential for efficient disulfide bond formation in the cytoplasm of E. coli. Microb Cell Fact 2010, 9:67.

30. Veggiani $\mathrm{G}$, de Marco A: Improved quantitative and qualitative production of single-domain intrabodies mediated by the co-expression of Erv1p sulfhydryl oxidase. Protein Expr Purif 2011, 79: 111-114

31. Hirvonen CA, Ross W, Wozniak CE, Marasco E, Anthony JR, Aiyar SE, Newburn VH, Gourse RL: Contributions of UP elements and the transcription factor FIS to expression from the seven rrn P1 promoters in Escherichia coli. J Bacteriol 2001, 183:6305-6314.

32. Faulkner MJ, Veeravalli K, Gon S, Georgiou G, Beckwith J: Functional plasticity of a peroxidase allows evolution of diverse disulfide-reducing pathways. Proc Natl Acad Sci U S A 2008, 105:6735-6740.

33. Rathnayaka T, Tawa M, Sohya S, Yohda M, Kuroda Y: Biophysical characterization of highly active recombinant Gaussia luciferase expressed in Escherichia coli. Biochim Biophys Acta 2010, 1804:1902-1907.

34. Stewart EJ, Katzen F, Beckwith J: Six conserved cysteines of the membrane protein $\mathrm{DsbD}$ are required for the transfer of electrons from the cytoplasm to the periplasm of Escherichia coli. EMBO J 1999, 18:5963-5971. 
35. Kohda J, Kawahara N, Fukuda H, Kondo A: Effect of oxidized and reduced forms of Escherichia coli DsbC on protein refolding. J Biosci Bioeng 2002, 94:130-134.

36. Liu X, Wang CC: Disulfide-dependent folding and export of Escherichia coli DsbC. J Biol Chem 2001, 276:1146-1151.

37. Bader MW, Hiniker A, Regeimbal J, Goldstone D, Haebel PW, Riemer J, Metcalf $P$, Bardwell JC: Turning a disulfide isomerase into an oxidase: DsbC mutants that imitate DsbA. EMBO J 2001, 20:1555-1562.

38. Schein $\mathrm{CH}$ : Optimizing protein folding to the native state in bacteria. Curr Opin Biotechnol 1991, 2:746-750.

39. Studier FW: Protein production by auto-induction in high density shaking cultures. Protein Expr Purif 2005, 41:207-234.

40. Molloy PE, Harris WJ, Strachan G, Watts C, Cunningham C: Production of soluble single-chain T-cell receptor fragments in Escherichia coli trxB mutants. Mol Immunol 1998, 35:73-81.

41. Waldo GS, Standish BM, Berendzen J, Terwilliger TC: Rapid protein-folding assay using green fluorescent protein. Nat Biotechnol 1999, 17:691-695.

42. Freedman RB, Hirst TR, Tuite MF: Protein disulphide isomerase: building bridges in protein folding. Trends Biochem Sci 1994, 19:331-336.

43. Zhan X, Schwaller M, Gilbert HF, Georgiou G: Facilitating the formation of disulfide bonds in the Escherichia coli periplasm via coexpression of yeast protein disulfide isomerase. Biotechnol Prog 1999, 15:1033-1038.

44. Chakravarthi S, Jessop CE, Willer M, Stirling CJ, Bulleid NJ: Intracellular catalysis of disulfide bond formation by the human sulfhydryl oxidase, QSOX1. Biochem J 2007, 404:403-411.

45. Rancy PC, Thorpe C: Oxidative protein folding in vitro: a study of the cooperation between quiescin-sulfhydryl oxidase and protein disulfide isomerase. Biochemistry 2008, 47:12047-12056.

46. Pedone E, D'Ambrosio K, De Simone G, Rossi M, Pedone C, Bartolucci S: Insights on a new PDI-like family: structural and functional analysis of a protein disulfide oxidoreductase from the bacterium Aquifex aeolicus. $J$ Mol Biol 2006, 356:155-164.

47. D'Ambrosio K, Pedone E, Langella E, De Simone G, Rossi M, Pedone C, Bartolucci S: A novel member of the protein disulfide oxidoreductase family from Aeropyrum pernix K1: structure, function and electrostatics. $J$ Mol Biol 2006, 362:743-752

48. Beeby M, O'Connor BD, Ryttersgaard C, Boutz DR, Perry LJ, Yeates TO: The genomics of disulfide bonding and protein stabilization in thermophiles. PLOS Biol 2005, 3:e309.

49. Dyson MR, Shadbolt SP, Vincent KJ, Perera RL, McCafferty J: Production of soluble mammalian proteins in Escherichia coli: identification of protein features that correlate with successful expression. BMC Biotechnol 2004, 4:32.

50. Hayhurst A: Improved expression characteristics of single-chain Fv fragments when fused downstream of the Escherichia coli maltosebinding protein or upstream of a single immunoglobulin-constant domain. Protein Expr Purif 2000, 18:1-10.

51. Jarchow S, Luck C, Gorg A, Skerra A: Identification of potential substrate proteins for the periplasmic Escherichia coli chaperone Skp. Proteomics 2008, 8:4987-4994.

52. Ha SC, Pereira JH, Jeong JH, Huh JH, Kim SH: Purification of human transcription factors Nanog and Sox2, each in complex with Skp, an Escherichia coli periplasmic chaperone. Protein Expr Purif 2009, 67:164-168.

53. Ritz D, Patel H, Doan B, Zheng M, Aslund F, Storz G, Beckwith J: Thioredoxin 2 is involved in the oxidative stress response in Escherichia coli. J Biol Chem 2000, 275:2505-2512.

54. Cabiscol E, Tamarit J, Ros J: Oxidative stress in bacteria and protein damage by reactive oxygen species. Int Microbio/ 2000, 3:3-8.

55. Storz G, Tartaglia LA, Ames BN: Transcriptional regulator of oxidative stress-inducible genes: direct activation by oxidation. Science 1990 248:189-194.

56. Francis DM, Page R: Strategies to optimize protein expression in E. coli. Curr Protoc Protein Sci 2010, Chapter 5: Unit 5 24 21-29.

57. Pan JL, Sliskovic I, Bardwell JC: Mutants in DsbB that appear to redirect oxidation through the disulfide isomerization pathway. $\mathrm{J} \mathrm{Mol} \mathrm{Biol} 2008$ 377:1433-1442.

58. Pioszak AA, Xu HE: Molecular recognition of parathyroid hormone by its $G$ protein-coupled receptor. Proc Natl Acad Sci U S A 2008, 105:5034-5039.

59. Daegelen P, Studier FW, Lenski RE, Cure S, Kim JF: Tracing ancestors and relatives of Escherichia coli $B$, and the derivation of $B$ strains REL606 and BL21(DE3). J Mol Biol 2009, 394:634-643.
60. Studier FW, Moffatt BA: Use of bacteriophage T7 RNA polymerase to direct selective high-level expression of cloned genes. J Mol Biol 1986 189:113-130.

61. Jobe A, Bourgeois S: lac Repressor-operator interaction. VI. The natural inducer of the lac operon. J Mol Biol 1972, 69:397-408.

62. Kudla G, Murray AW, Tollervey D, Plotkin JB: Coding-sequence determinants of gene expression in Escherichia coli. Science 2009, 324:255-258.

63. Stock JB, Rauch B, Roseman S: Periplasmic space in Salmonella typhimurium and Escherichia coli. J Biol Chem 1977, 252:7850-7861.

64. Alvarez FA, Georgellis D: In Vitro and In Vivo Analysis of the ArcB/A Redox Signaling Pathway. Methods Enzymol 2010, 471:205-226.

65. Bekker M, Alexeeva S, Laan W, Sawers G, Teixeira de Mattos J, Hellingwerf K: The ArcBA two-component system of Escherichia coli is regulated by the redox state of both the ubiquinone and the menaquinone pool. $J$ Bacteriol 2010, 192:746-754.

66. Boyd D, Weiss DS, Chen JC, Beckwith J: Towards single-copy gene expression systems making gene cloning physiologically relevant: lambda InCh, a simple Escherichia coli plasmid-chromosome shuttle system. J Bacteriol 2000, 182:842-847.

67. Boyd D, Manoil C, Beckwith J: Determinants of membrane protein topology. Proc Natl Acad Sci U S A 1987, 84:8525-8529.

68. Mössner E, Huber-Wunderlich M, Rietsch A, Beckwith J, Glockshuber R, Aslund F: Importance of redox potential for the in vivo function of the cytoplasmic disulfide reductant thioredoxin from Escherichia coli. J Biol Chem 1999, 274:25254-25259.

doi:10.1186/1475-2859-11-56

Cite this article as: Lobstein et al:: SHuffle, a novel Escherichia coli protein expression strain capable of correctly folding disulfide bonded proteins in its cytoplasm. Microbial Cell Factories 2012 11:56.

\section{Submit your next manuscript to BioMed Central and take full advantage of:}

- Convenient online submission

- Thorough peer review

- No space constraints or color figure charges

- Immediate publication on acceptance

- Inclusion in PubMed, CAS, Scopus and Google Scholar

- Research which is freely available for redistribution 